\title{
DISCLOSURE E TRANSPARÊNCIA NO SETOR PÚBLICO: UMA ANÁLISE DA CONVERGÊNCIA DOS PRINCÍPIOS DE GOVERNANÇA
}

\section{DIVULGACIÓN Y TRANSPARENCIA EN EL SECTOR PÚBLICO: UN ANÁLISIS DE LA CONVERGENCIA DE LOS PRINCIPIOS DE GOBIERNO}

\begin{abstract}
Luzia Zorzal - luzia.zorzal@gmail.com Doutora em Ciência da Informação pela Universidade de Brasília (UnB). Professora Professora da Universidade Federal do Espírito

Santo (UFES).

Georgete Medleg Rodrigues - medleg.georgete@gmail.com Doutora em História pela Université de Paris. Professora do Programa de Pós-graduação em Ciência da Informação da Universidade de Brasília (UnB).
\end{abstract}

\section{RESUMO}

Introdução: Estudos sobre disclosure das instituições privadas são frequentes, mas não ocorrem quando se trata das instituições públicas, onde a divulgação de informações da gestão é ainda muito limitada.

Objetivo: $O$ artigo parte de uma pesquisa de doutorado em Ciência da Informação em andamento, investiga os princípios de disclosure e transparência à luz das boas práticas de governança aplicadas ao setor público para redução da assimetria da informação e apresenta um recorte da referida pesquisa.

Metodologia: Os procedimentos metodológicos consistiram em pesquisa bibliográfica e análise de conteúdo para identificar os princípios e padrões de boas práticas de governança recomendados para a administração pública, objetivando sistematizar essas recomendações como instrumentos de governança e verificar a convergência dos princípios de disclosure e transparência.

Resultados: Os resultados parciais demonstram convergência dos princípios disclosure e transparência. 
Conclusões: Indicam que as instituições públicas devem se preocupar em implantar as práticas de boa governança como forma de mitigar a assimetria informacional.

Palavras-chave: Transparência. Disclosure. Governança. Acesso à informação. Assimetria da informação. Setor público.

\section{INTRODUÇÃO}

Temas como transparência, acesso à informação, accountability e governança ganharam centralidade na agenda política nacional. A transparência e o acesso à informação pública estão previstos como direitos do cidadão e deveres do Estado na Constituição Federal (CF) de 1988 (BRASIL, 1988) e em outras legislações. A disponibilização transparente da informação é um dos mecanismos que garantem a promoção desses direitos, fortalecem a democracia, ampliam o exercício da cidadania, ajudam a promover o controle social, inibem a corrupção, entre outros.

Horizontalidade, transparência, fluidez, flexibilidade, autonomia dos atores e civismo são elementos que se teceram em torno do paradigma central das instituições bem como na crença no poder das Tecnologias de Informação e Comunicação (TICs) para revolucionar totalmente as relações sociais. A estabilidade das formas de organização e de direção e a perenidade da localização geográfica do poder se desvanecem diante do imperativo de adaptabilidade constante e da tendência a tudo deslocalizar. As palavras-chave são integração e ubiquidade. A transgressão das fronteiras é seu resultado, sejam elas físicas, sejam funcionais. Há interpenetração local, nacional e global (MATTELART, 2002).

As instituições públicas e privadas estão passando por grandes transformações em virtude da dinâmica desses processos. As intensas mudanças que se verificam nas relações socioeconômicas e nos 
procedimentos, especialmente aqueles ligados, por um lado, à produção e divulgação e, por outro, à decodificação e interpretação das informações, se tornaram questões-chave na contemporaneidade.

Nesse contexto, configuram-se e exigem-se novos modelos e instrumentos institucionais, normativos e reguladores bem como novas políticas industriais, tecnológicas e de inovação que sejam capazes de dar conta das questões que se apresentam à nova realidade sociotécnica e econômica.

Com o advento da chamada era da informação, muitas das proposições e regulações da era industrial tornaram-se ultrapassadas. Kaplan e Norton (1997), por exemplo, afirmam que o ambiente da era da informação exige novas capacidades para assegurar o sucesso competitivo. Nesse sentido, 0 atual desenvolvimento do sistema capitalista pressiona para que a gestão se aprimore, pois os usuários necessitam de informações úteis, ágeis e precisas para acompanhar as mudanças que se verificam no cenário econômico, ambiental, social, político, cultural e tecnológico. Os ambientes sofrem transformações ao interagirem com a informação assim como o comportamento das pessoas, produzindo desafios para os gestores. A maior conscientização das sociedades na busca por informações qualificadas requer que as instituições tenham maior comprometimento com a prática de ações de responsabilidade social e sua evidenciação.

Mudanças decorrentes da revolução tecnológica, por sua vez, refletem no Estado, no governo e na sociedade, provocando conflitos e a exigência de uma atuação mais ampla do governo, não apenas voltada para a eficiência, mas, sobretudo, para a equidade, a justiça social, o desenvolvimento sustentável, o combate à pobreza e à corrupção e a promoção do desenvolvimento humano. Esse cenário requer que o Estado atue de forma transparente na busca de resultados efetivos para entregar eficaz accountability (MATIAS-PEREIRA, 2010b).

Embora a temática disclosure da informação em instituições privadas venha sendo objeto de estudo, isso não ocorre quando se trata 
das instituições públicas, onde a divulgação da gestão é ainda muito limitada, apesar da sua importância social e do recebimento de significativos recursos públicos. A informação sob a tutela do Estado é um bem público e sua evidenciação deve ser por iniciativa da administração pública, de forma espontânea, proativa, independente de qualquer solicitação, ou seja, transparência ativa, como definido em lei. Cabe, portanto, a essas instituições identificar aquilo que é mais demandado pela sociedade e anteciparem-se para disponibilizar isso proativamente na Internet e/ou outros meios, a fim de facilitar que os stakeholders (partes interessadas) encontrem essa informação evitando custos tanto para as instituições, quanto para os stakeholders.

No Brasil, os entes públicos são obrigados pela CF/1988 a prestar contas do uso de recursos públicos e a respeitar o princípio da publicidade, entre outros. A cobrança por mais transparência pública, nos últimos anos, tem avançado de forma progressiva. Além da CF/1988, a transparência também está contemplada na Lei no 101, de 4 de maio de 2000 (BRASIL, 2000), denominada Lei de Responsabilidade Fiscal (LRF), e na Lei № 131, de 27 de maio de 2009 (BRASIL, 2009), chamada de Lei da Transparência; e o acesso à informação é normatizado pela Lei oㅜ 12.527, de 18 de novembro de 2011 (BRASIL, 2011), denominada Lei de Acesso à Informação (LAI), e pelo Decreto $n^{\circ}$ 7.724, de 16 de maio de 2012 (BRASIL, 2012), que regulamenta a LAI. O Tribunal de Contas da União (TCU) divulgou em 2014 o Referencial Básico de Governança (RBG) que estabelece práticas de gestão, aplicável a órgãos e entidades da administração pública (BRASIL, 2014).

A LAl é recente. Em termos históricos, praticamente metade das leis de acesso à informação do mundo foi promulgada na última década. Apenas a Suécia formalizou uma lei antes de 1950 (em 1766). À medida que avançam as tecnologias e as instituições, os paradigmas associados à abertura continuam a se transformar e os espaços para a inovação a se expandir (MICHENER, 2011). 
A transparência poderá ajudar a promover uma administração pública mais aberta à participação social e a colaborar na transição da cultura do segredo para a cultura de acesso à informação, com disponibilização proativa de dados e informações. A LAl é um instrumento a mais que promove a cultura do disclosure, da transparência, da abertura, da accountability, que são princípios fundamentais nas organizações públicas, além de auxiliar na luta contra a corrupção. No entanto, será necessário assegurar a sua efetividade.

\section{METODOLOGIA}

Buscou-se analisar os princípios de disclosure e transparência à luz das boas práticas de governança aplicadas ao setor público, com base na literatura sobre o tema, com o objetivo de verificar o nível de convergência desses princípios. Por meio de pesquisa bibliográfica e da análise de conteúdo (BARDIN, 2004), focalizou-se a dimensão conceitual para detectar as distintas concepções e mecanismos estabelecidos para a administração pública. Tratando-se de um recorte da pesquisa de doutorado, o foco recaiu sobre os instrumentos de governança para o setor público, elaborados por instituições internacionais e brasileiras, cobrindo o período de $2004^{1}$ a 2014. Para identificação desses instrumentos, foi pesquisado o sítio eletrônico da European Corporate Governance Institute (ECGI, 2014), além de diversos sítios de organizações multilaterais e, no caso brasileiro, o sítio do TCU. O tratamento e análise dos dados foram feitos por meio de um quadro onde foram consolidados os princípios de boa governança estabelecidos por nove instituições que teorizam e definem mecanismos

\footnotetext{
1 O primeiro instrumento de boas práticas de governança no setor público, identificado na literatura, foi divulgado em 2003, pela Australian National Audit Office (ANAO). No entanto, em 2014, a ANAO publicou nova versão, cujos dados constaram das instituições analisadas.
} 
de boa governança para o setor público, com destaque para a análise da dimensão relacionada com o disclosure e a transparência.

\section{CONCEITOS DE DISCLOSURE E TRANSPARÊNCIA}

A centralidade da informação no mundo contemporâneo indica que ela ocupa uma dimensão planetária e um espaço social que é inerentemente dinâmico. A produção, a organização e a disseminação da informação são impulsionadas pelas TICs. O disclosure, a abertura e a transparência juntamente com o acesso à informação devem ser socializados e democratizados. Para que a informação seja apreendida pela sociedade, ela necessita estar disponibilizada, ou melhor, divulgada (disclosure) tempestivamente, ter abertura, ser compreensível, apresentar elevado grau de precisão, ser transparente para que se possa entregar eficaz accountability.

Disclosure é considerado um tópico bastante abrangente. Engloba toda a área de informação financeira e envolve questões como: público-alvo; finalidade; níveis de disclosure e seus respectivos padrões; formas e métodos; periodicidade; obrigatoriedade ou não; entre outras. Neste artigo serão abordados apenas os aspectos conceituais, delimitação válida também para o termo transparência.

Quanto ao termo disclosure, não se tem uma tradução satisfatória para o português. Muitos o traduzem como divulgação, evidenciação, veiculação de informação. Gibbins, Richardson e Waterhouse (1990) definem disclosure como qualquer divulgação intencional de informação financeira, tanto quantitativa quanto qualitativa, obrigatória ou voluntária, difundida por canais formais ou informais. Williams (2008) propõe uma definição mais ampliada para considerar todos os tipos (social, ambiental e financeiro) e formas (obrigatória e voluntária) de disclosure e ainda se refere ao disclosure corporativo. Além disso, segundo Williams, destina-se a uma grande variedade de stakeholders. 0 disclosure corporativo é definido por Williams (2008, p. 237) como: 
[...] qualquer divulgação pública intencional de informação financeira, social ou ambiental, obrigatória ou voluntária, qualitativa ou quantitativa - que é susceptível de ter um impacto no desempenho competitivo da empresa e na estratégica de tomada de decisões de seus públicos internos e externos (tradução nossa).

Desse modo, as instituições públicas vivenciam essas questões, uma vez que os cidadãos têm dificuldades na obtenção de indicadores econômicos, sociais e ambientais dessas instituições, revelando que o disclosure é essencial para que se possa conhecê-las um pouco mais. Nesse sentido, Murcia (2009, p. 22) destaca que "[...] o nível de assimetria informacional diminui à medida que se aumenta o nível de divulgação, ou seja, possuem uma relação inversa."

O termo transparência assumiu novos significados e ganhou popularidade. É evidente que todos desejam que tanto as instituições públicas quanto as privadas sejam o mais transparente possível. Porém, como alertam Bennis et al. (2008), apesar das promessas de transparência, é comum a percepção de que não estão contando tudo que se precisa saber ou se tem o direito de saber. Ele afirma ainda que a revolução digital, ocorrida nas últimas décadas, tornou a transparência inevitável no mundo inteiro. Com a Internet, celulares com câmeras e outros dispositivos móveis, democratizou-se o poder, deslocando-o dos poucos indivíduos de grande visibilidade para as muitas pessoas que têm a tecnologia à disposição.

A transparência com um novo significado teve um grande salto com a disseminação das boas práticas de governança que têm relação sobre o modo como as instituições são administradas e controladas.

Após os anos 1970, a transparência adquire seu lugar de destaque no discurso administrativo em países norte-americanos e da Europa ocidental, tornando-se um dos valores essenciais da administração pública e configurando-se como um eixo privilegiado do reformismo administrativo que fez da transparência o princípio e do segredo, a exceção (JARDIM, 1999). 
Existem muitas definições de transparência e elas diferem dependendo do contexto. De acordo com o Instituto Brasileiro de Governança Corporativa (IBGC, 2009), transparência significa a disponibilização para as partes interessadas das informações que sejam de seu interesse e não apenas aquelas impostas por disposições legais. Deve contemplar tanto os dados econômico-financeiros quanto os não econômico-financeiros (inclusive intangíveis) que conduzem a ação gerencial. A adequada transparência traz um clima de confiança internamente e também nas relações da empresa com os stakeholders.

Fox (2007), dentre outras abordagens acerca de transparência, classifica-a em duas categorias: proactive e demand-driven. A disseminação proativa (proactive) reporta-se à informação que 0 governo torna pública sobre suas atividades e seu desempenho; e acesso passivo (demand-driven) refere-se ao compromisso institucional para responder às solicitações dos cidadãos para tipos específicos de informação ou documentos, pois, do contrário, não seria possível acessá-los. Com relação à disseminação proativa e ao acesso passivo, o Decreto n 7.724, de 2012 (BRASIL, 2012), que regulamentou a LAI, também utiliza estas abordagens: transparência ativa - quando a administração pública divulga informações à sociedade por iniciativa própria, de forma voluntária, independente de qualquer solicitação - e transparência passiva - quando divulga informações sob demanda, em atendimento às solicitações dos stakeholders.

Jardim (1999, p. 51) expõe sobre opacidade e transparência e as suas gradações. Alerta que "[...] a riqueza teórica destas noções convida-nos a que nos desviemos da aparente facilidade com que tendem a ser mapeadas estas zonas de luz e sombra". Essa concepção encontra-se presente em Chevalier (1998) que vê a transparência como suscetível de graus, ou seja, um corpo pode ser realmente: transparente - os objetos que recobre aparecem com nitidez; translúcido - não permite distinguir nitidamente os objetos; ou diáfano - não possibilita identificar a forma desses objetos. Na visão de Chevalier (1998), a 
transparência é carregada de opacidade e isso a transforma em "verdadeiro mito". No entanto, considerando-se os vários mecanismos de governança divulgados nas últimas décadas, entende-se que 0 disclosure e a transparência tornar-se-ão realidade.

Na perspectiva de Tapscott e Ticoll (2005, p. 11), a transparência é uma antiga força com novo poder que tem implicações de longo alcance para todo o mundo. "Ela vai muito além da obrigação de revelar informações financeiras básicas". Os autores definem transparência "[...] como a acessibilidade, para os stakeholders, às informações institucionais referentes a assuntos que afetem seus interesses." (TAPSCOTT; TICOLL, 2005, p. 23).

Rodrigues (2013, p. 424) argumenta que, na atualidade, "[...] a noção de transparência já está incorporada - embora não inteiramente praticada pelos governos e instituições - como uma premissa para o bom funcionamento da administração pública".

Schnackenberg e Tomlinson (2014) sustentam que a transparência não é unidimensional e sim composta de três dimensões específicas: disclosure (divulgação), clareza e acurácia da informação.

Para se obter disclosure e transparência, diversos organismos nacionais e internacionais sugerem o mecanismo da governança, cujos aspectos serão detalhados nas seções seguintes. Para a governança, existem várias teorias que explicam suas práticas. Entre elas, destacase a teoria do agente-principal que será abordada no próximo tópico.

\section{TEORIA DO AGENTE-PRINCIPAL}

O estudo do tópico governança remete ao entendimento das teorias relacionadas com o tema. Neste artigo, será utilizada a teoria do agente-principal que, segundo Silveira (2010), corroborado por MatiasPereira (2010b), é uma das mais aceitas conceitualmente e a principal abordagem formal para se analisar a temática da governança e é 
também a mais utilizada para explicar os conflitos de interesses nas instituições e seus potenciais impactos para as partes interessadas.

Os problemas associados à governança possuem suas raízes históricas no desenvolvimento teórico ocorrido na economia, na chamada teoria da firma, base da teoria do agente-principal. Vários estudos foram desenvolvidos, no século $X X$, sobre a teoria da firma: Coase (1937), Alchian e Demsetz (1972), Ross (1973), entre outros. Pela teoria da firma, a empresa é percebida como um conjunto de contratos estabelecidos entre os seus integrantes (acionistas, investidores, fornecedores, clientes, governo etc.). Cada integrante colabora com a firma e recebe algo em troca.

A teoria do agente-principal, geralmente denominada teoria da agência, preocupa-se principalmente com o problema agente versus principal, também cunhado na literatura como conflitos de agência, que se relacionam com os princípios fundamentais, sintetizados por Klein (1983), que afirma que não há contrato completo, e por Jensen e Meckling (1976) para quem não há agente perfeito. Em outras palavras, para eles, existe uma relação estabelecida como um contrato sobre o qual uma ou mais pessoas (o principal) contratam outra pessoa (o agente) para desempenhar algum serviço ou trabalho em nome dos contratantes, abrangendo a delegação de autoridade para a tomada de decisão pelo agente.

Com base na teoria desenvolvida, os gestores (agentes) contratados tenderiam a agir de forma a maximizar seus próprios benefícios (maiores salários, maior estabilidade no emprego, mais poder etc.), agindo em interesse próprio e não segundo os interesses da instituição e das demais partes interessadas (principais). Para reduzir o problema, os autores sugeriram que as instituições deveriam adotar uma série de medidas para alinhar interesses dos envolvidos, objetivando, principalmente, o sucesso da organização. Para tanto, foram estabelecidas medidas que incluíam práticas de monitoramento, controle 
e ampla divulgação de informações. A esse conjunto de práticas convencionou-se denominar Governança Corporativa (GC).

Berle e Means, no clássico The modern corporation and private property, chamaram a atenção, no início da década dos anos 1930, para a dispersão do capital das empresas e para o divórcio entre a propriedade e a gestão, caracterizando, dessa forma, o problema que atualmente se denomina GC, o qual se centrou no conflito de agência. Quando há separação entre controle e propriedade, ocorre delegação de autoridade que envolve dois atores, um chamado agente e o outro, principal. O problema de agência era tido como conflito entre os administradores (agentes executivos) e os acionistas (agentes principais). Desse modo, os conflitos de agência é uma das razões do desenvolvimento da GC (ROSSETTI; ANDRADE, 2012). Como afirma Marques (2007, p. 13), a GC "[...] é um conjunto de regras que visam a minimizar os problemas de agência".

De forma análoga, no setor público, a relação entre o gestor (o agente) e o eleitor, ou seja, o cidadão (o principal), poderá ser caracterizada como uma relação de agência (ROSS, 1973; SLOMSKI, 2005; SLOMSKI et al., 2008).

A transposição da teoria do agente-principal para o setor público também é proposta por Rossetti e Andrade (2012), colocando o contribuinte como principal e os gestores públicos como agentes para o modelo de governança pública. São os cidadãos contribuintes que canalizam recursos para o Estado, capitalizando-o para que ele produza bens e serviços de interesse público. Esses autores sublinham que:

[...] a questão-chave do Estado não é de governabilidade, mas de governança. Enquanto a primeira é uma conquista circunstancial e geralmente efêmera do poder estabelecido, a segunda é uma conquista da sociedade, estrutural e duradoura. E que estará necessariamente alicerçada nos quatro princípios que definem a boa governança das corporações: fairness, disclosure, accountability e compliance (ROSSETTI; ANDRADE, 2012, p. 578, grifo dos autores). 
As questões contempladas pela teoria agente-principal estão relacionadas com a existência de informação assimétrica entre agenteprincipal. A assimetria ocorre quando uma das partes (agente) possui mais informação em detrimento da outra parte (principal). Esse fenômeno acontece porque o agente tende a estar mais diretamente vinculado às operações diárias da instituição do que o principal, além de outros fatores próprios da dinâmica das sociedades contemporâneas.

Stiglitz (2002), ganhador, em 2001, do Prêmio Nobel de Economia, juntamente com outros dois colegas, em função de seus estudos a respeito das implicações econômicas da assimetria de informações, explica que há uma assimetria natural de informações entre os que governam e os que são governados muito parecida com a assimetria informacional existente entre os gestores das empresas e seus acionistas.

Em sociedades democráticas, os cidadãos têm o direito básico de saber, de se expressarem, de serem informados sobre o que o governo está fazendo, sobre as motivações e também de debater o assunto. Essas sociedades pressupõem a transparência e abertura por parte dos governos. No entanto, reconhece-se que, em proveito próprio, governos e seus líderes não incentivam o disclosure e a disseminação de informações contrárias a seus interesses, assinala Stiglitz (2002).

Além de não ser possível monitorar todos os agentes, é preciso considerar também que o modelo teórico agente-principal aplicado à gestão pública tende a ignorar diferenciais de recursos materiais, informacionais, simbólicos e cognitivos, ao tratar ambos os lados da relação como se fossem constituídos por indivíduos racionais e simétricos (MIGUEL, 2014).

Nesse contexto, Slomski et al. (2008) sublinham a circunstância em que os gestores dispõem de informação privilegiada acerca das instituições nas quais atuam em detrimento da sociedade, o que se constitui em elementos geradores de assimetria no processamento das informações disponibilizadas. 


\section{GOVERNANÇA}

A governança é um dos temas que vêm ocupando a agenda dos gestores atuais e está entre os mais importantes desafios para instituições públicas ou privadas. Conforme pesquisa no sítio eletrônico da European Corporate Governance Institute (ECGI, 2014), no índice de códigos de governança, em que 94 países e mais sete instituições disponibilizam seus códigos, a maioria deles foca mais o setor privado, que trata da GC. Nesse sítio eletrônico, apenas os Países Baixos e a Organisation for Economic Co-operation and Development (OECD) contavam com instrumentos de governança especificamente voltados para o setor público. Dessa forma, a GC, que é mais focada nas organizações do setor privado, possui muito mais instrumentos de análise do que o setor público.

Governança (governance) foi conceituada pelo World Bank (1992, p. 1, tradução nossa) como "[...] a maneira como o poder é exercido na gestão dos recursos econômicos e sociais para o desenvolvimento de um país". "Boa governança" é sinônimo de "gestão de desenvolvimento."

Nos limites deste artigo e considerando que o foco são o disclosure e a transparência, não será feita uma apresentação detalhada e profunda do tema governança. Serão vistos apenas os aspectos conceituais relacionados com a compreensão dos seus princípios de governança, mais especificamente do disclosure e da transparência.

\subsection{Governança corporativa: surgimento e marcos construtivos}

Apesar de ser uma área nova, seu desenvolvimento tem sido afetado por teorias de vários campos, como: finanças, economia, contabilidade, direito, gestão, comportamento organizacional, ciência da informação, entre outras (MALLIN, 2013). 
O trabalho de Berle e Means é frequentemente citado (ROSSETTI; ANDRADE, 2012; MALLIN, 2013 e outros) e reconhecido como uma das bases conceituais da GC.

Rossetti e Andrade (2012) evidenciam que, embora a GC já se revelasse nas mais avançadas abordagens sobre economias industriais do Ocidente desde as primeiras décadas do século XX, quando se desencadearam os processos de dispersão do capital e de separação da propriedade e da gestão, somente alcançou maior visibilidade nas últimas décadas, com movimentos quase simultâneos, denominados os grandes marcos construtivos da governança corporativa, quais sejam: a) o ativismo pioneiro de Robert A. G. Monks, em 1992; b) o Relatório Cadbury, também de 1992; c) os princípios da OECD (2004) aprovados em 1999; e d) a Lei Sarbanes-Oxley (SOX) promulgada em 2002.

A discussão da transparência na Ciência Organizacional teve início aproximadamente no meio do século XX. O maior salto se deu com a crise de confiança de 2002, devido às fraudes contábeis e financeiras de algumas empresas, como Enron (2001), WorldCom (2002), Arthur Andersen (2002), Lehman Brothers (2008), entre outras. A resposta foi a SOX, novas regras dos Conselhos de Normas Contábeis e uma explosão de reformas na GC (TAPSCOTT; TICOLL, 2005; SCHNACKENBERG; TOMLINSON, 2014).

\subsection{Conceitos de Governança Corporativa}

Observa-se que, apesar de a GC ser um assunto novo, a literatura nos brinda com uma enorme diversidade de conceitos. Rosseti e Andrade (2012) sintetizaram conceitos de renomados autores sobre governança, reunindo-os em quatro grupos, com as seguintes perspectivas:

a) guardiã de direitos (das partes com interesses em jogo, nas instituições); 
Luzia Zorzal; Georgete Medleg Rodrigues

Disclosure e transparência no setor público: uma análise da convergência dos princípios de governança

b) sistema de relações (pelo qual as sociedades são dirigidas e monitoradas);

c) estrutura de poder (que se observa no interior das corporações);

d) sistema normativo (que rege as relações internas e externas das companhias).

Com essas perspectivas elencadas, partindo de uma concepção abrangente e a partir do conjunto de conceitos de vários autores, destacaram expressões-chave que apareceram nas definições usuais e apresentaram uma tentativa de síntese conceitual para a GC:

[...] a governança corporativa é um conjunto de princípios, propósitos, processos e práticas que rege o sistema de poder e os mecanismos de gestão das empresas abrangendo: propósitos dos proprietários; sistema de relações proprietários-conselho-direção; maximização do retorno total dos proprietários, minimizando oportunismos conflitantes com este fim; sistema de controle e de fiscalização das ações dos gestores; sistema de informações relevantes e de prestação de contas às partes interessadas nos resultados corporativos; sistema guardião dos ativos tangíveis e intangíveis das companhias (ROSSETTI; ANDRADE, 2012, p. 141).

Em muitos países, nas últimas décadas, o tema governança tem sido intensificado por iniciativas institucionais relevantes. O Instituto Brasileiro de Governança Corporativa (IBGC, 2009), organização exclusivamente dedicada à promoção da GC no Brasil e fomentadora das práticas e discussões sobre o tema, com o propósito de contribuir para o desempenho sustentável das organizações e influenciar os agentes da sociedade, objetivando maior transparência, justiça e responsabilidade, emitiu, em 1999, o primeiro Código de melhores práticas de GC. O código atual, em sua 4ạ edição, lançado em 2009, engloba não apenas empresas, mas também qualquer tipo de organização e apresenta o seguinte conceito para GC: 
É o sistema pelo qual as organizações são dirigidas, monitoradas e incentivadas, envolvendo os relacionamentos entre proprietários, Conselho de Administração, Diretoria e órgãos de controle. As boas práticas de Governança Corporativa convertem princípios em recomendações objetivas, alinhando interesses com a finalidade de preservar e otimizar o valor da organização, facilitando seu acesso a recursos e contribuindo para sua longevidade (IBGC, 2009, p. 19).

O empenho pela GC é disseminado pela proposição de boas práticas por mais de um canal institucional e por vários países.

\subsection{Princípios Básicos de Governança Corporativa}

Considerando os vários estudos que abordam o tema GC, destacam-se os valores que thes dão sustentação, sintonizando concepções, práticas e processos de alta gestão, os quais são denominados princípios básicos de GC ou, conforme Rossetti e Andrade (2012), princípios essenciais: a) Fairness (equidade); b) Disclosure and Transparency (divulgação e transparência); c) Accountability (prestação de contas); d) Compliance (responsabilidade corporativa).

Existem diversas instituições que apresentaram instrumentos (padrões, códigos, diretrizes, guias, manuais, orientações etc.) estabelecendo princípios de GC (IBGC, 2009; OECD, 2004; entre outras).

\subsection{Governança no Setor Público}

A gestão pública tem suas complexidades e especificidades que a distinguem das organizações privadas, exigindo habilidades $\mathrm{e}$ conhecimentos específicos. Deve estar associada à melhoria da qualidade dos serviços prestados aos cidadãos, além da perspectiva econômica e financeira. A questão da democracia e seus aperfeiçoamentos não se separa da gestão pública, procurando incentivar a participação dos stakeholders e tornar suas ações 
transparentes e submetidas a um efetivo controle social (NOGUEIRA, 1998).

Com o objetivo de aprimorar o desempenho das instituições, mitigar conflitos, alinhar ações e trazer mais segurança para a sociedade, estudos estão sendo desenvolvidos no sentido de aplicar as práticas de governanças - já bastante utilizadas na iniciativa privada também no setor público.

Embora o termo governança date de idades remotas, o conceito e a importância que atualmente Ihe são atribuídos foram construídos nas últimas três décadas, principalmente nas organizações privadas, onde a governança inicialmente foi aplicada. Segundo a International Federation of Accountants (IFAC, 2001), de modo geral, a GC se refere à gestão, ao controle das empresas e seus respectivos relatórios, para o benefício das partes interessadas e está alicerçada pelos princípios de transparência, integridade e accountability. No entanto, recentemente, tem recebido atenção em todos os setores e em nível mundial.

As entidades governamentais operam em um contexto diferente $\mathrm{e}$ são, portanto, confrontadas com outras questões, como: variados stakeholders, diversas exigências sobre abertura e transparência, diferentes estruturas organizacionais etc. Contudo, a natureza dos problemas é semelhante (NETHERLANDS, 2000).

Para alguns países, o termo GC pode ser interpretado como relativo ao setor privado, pois foi nessa área que primeiramente foi aplicado. Algumas jurisdições utilizam a expressão governança governamental (government governance) para descrever a governança no setor público (IFAC, 2001). Contudo, na literatura sobre o assunto, o termo governança corporativa também é utilizado no setor público.

A expressão governança pública é polissêmica, logo seu significado varia conforme o campo de estudo e até mesmo dentro de áreas específicas do conhecimento. Além da variação de significado, a governança pode ser analisada por diferentes perspectivas, delimitadas em função do nível de abrangência no amplo contexto das relações 
entre Estado, governo e sociedade. Edwards (2012) propôs a seguinte classificação para o termo governança: nível macro - governança pública; nível médio - governança no setor público; nível micro governança corporativa (ou organizacional).

Governança pública é compreendida por Matias-Pereira (2010b, p. 113) "[...] como o sistema que determina o equilíbrio de poder entre todos os envolvidos numa organização - governantes, gestores, servidores, cidadãos - com vista a permitir que o bem comum prevaleça sobre os interesses de pessoas ou grupos." A instituição, ao se desenvolver e atingir um melhor desempenho, alcança seus objetivos, que resultam em satisfação para todos os atores envolvidos. Desse modo, fomenta a boa governança, tornando-se confiável e legitimável perante a sociedade.

Os primeiros estudos sobre a governança no setor público, identificados na literatura, foram o dos Países Baixos (NETHERLANDS, 2000) publicado no ano de 2000 e, o "Study 13" editado pela IFAC (2001), em 2001.

Em 2014, a IFAC e a Chartered Institute of Public Finance and Accountancy (CIPFA) publicaram o International Framework: Good Governance in the Public Sector em que acrescentaram a dimensão sobre a obtenção de resultados econômico, social e ambiental sustentáveis como um foco importante nos processos e estuturas de governança. Destacaram também o foco de longo prazo para a responsabilidade dos gestores, pois eles devem levar em conta 0 impacto de suas ações e decisões atuais sobre as futuras gerações.

Diversos órgãos, como a OECD, o International Monetary Fund (IMF ou Fundo Monetário Internacional), o World Bank (Banco Mundial), o Institute of Internal Auditors (IIA ou Instituto de Auditores Internos), o Australian National Audit Office (ANAO ou Escritório de Auditoria Nacional da Austrália), o Centro Latinoamericano de Administración para el Desarrollo (CLAD ou Centro Latino-Americano de Administração para 
o Desenvolvimento), entre outros, realizam estudos sobre governança no setor público, além dos já referenciados.

Até recentemente, o Brasil carecia de um Código de Governança para o setor público. As discussões em torno desse assunto eram pautadas tanto no Código das Melhores Práticas de GC do IBGC quanto nos códigos de órgãos multilaterais.

Não obstante, em 9 de junho de 2014, o TCU disponibilizou, por meio de seu sítio eletrônico, o RBG denominado Governança Pública: referencial básico de governança aplicável a órgãos e entidades da administração pública e ações indutoras de melhoria (BRASIL, 2014). Além do RBG, o Brasil dispõe de exigências legais que tratam da transparência e do acesso à informação e, consequentemente, direta ou indiretamente, da governança.

\subsection{Conceitos de governança no setor público}

A importância da boa governança no sucesso das organizações é crescente, assim como a quantidade de trabalhos sobre esse assunto no setor privado, enquanto a literatura sobre esse tema no setor público é bem menos frequente.

Ao contextualizar o setor público, a IFAC (2001) destaca que é um setor complexo, suas entidades não operam dentro de uma estrutura legislativa comum nem possuem forma e tamanho organizacional padrão. É importante, portanto, reconhecer a diversidade do setor público e os diferentes modelos de governança que se aplicam em diferentes países e em diferentes setores. Cada qual tem características únicas que requerem atenção especial e impõem diferentes conjuntos de responsabilidades.

Em seu estudo mais recente, International Framework: Good Governance in the Public Sector, a IFAC afirma que a governança no setor público "[...] compreende a estrutura (administrativa, política, econômica, social, ambiental, legal e outras) posta em prática para 
assegurar que os resultados pretendidos para os stakeholders sejam definidos e alcançados." (IFAC, 2014, p. 8, tradução nossa).

Por meio do RBG do TCU, é apresentada a seguinte definição para governança no setor público: “[...] um conjunto de mecanismos de liderança, estratégia e controle postos em prática para avaliar, direcionar e monitorar a gestão, com vistas à condução de políticas públicas e à prestação de serviços de interesse da sociedade." (BRASIL, 2014, p. 10, grifo do autor).

Como se pode observar nas definições apresentadas de governança para o setor público, a sociedade e/ou os stakeholders estão contemplados e, para que isso aconteça de maneira plena, os princípios de disclosure e transparência são de importância fundamental. A seguir, serão apresentados os princípios de governança sob a ótica do setor público.

\subsection{Princípios de Governança no Setor Público}

A boa governança pública, a exemplo da corporativa, está apoiada nos quatro princípios básicos: fairness (equidade), disclosure and transparency (divulgação e transparência), accountability (prestação de contas) e compliance (responsabilidade corporativa). Matias-Pereira (2010a) salienta que a busca permanente da prática desses princípios na gestão de um país ou de qualquer instituição deve ser vista como uma condição fundamental para que o país ou a instituição possam continuar a progredir. É uma tarefa permanente, que exige uma participação proativa de todos os atores envolvidos - dirigentes, políticos, órgãos de controle - e, em especial, da sociedade organizada.

Concordando, portanto, com o argumento de Matias-Pereira (2010a), buscou-se extrair maior clareza e densidade analítica dos diversos princípios estabelecidos pelas instituições que teorizam e definem mecanismos para a obtenção de boa governança. Para tanto, construiu-se um quadro comparativo visando a consolidar as 
contribuições advindas das diferentes instituições. Como parâmetro para a consolidação, foram considerados os princípios de governança para o setor público, desenvolvidos pela IFAC (2014). Com efeito, o Quadro 1 mostra, comparativamente, as contribuições das seguintes instituições e/ou órgãos para o setor público: CIPFA (2004), CLAD (2006), IMF (2007), Netherlands (2009), Unidet States (2011), IIA (2012), ANAO (2014), IFAC (2014) e TCU (BRASIL, 2014).

Em sua versão mais recente, a IFAC (2014) apresenta seus princípios em sete dimensões ( $\mathbf{A}$ a $\mathbf{G}$ ). Ademais, ressalta-se que no setor público a função fundamental da boa governança é assegurar que as entidades alcancem os resultados previstos, agindo no interesse público, constantemente. Agir no interesse público implica considerar os princípios $\mathbf{A}$ e $\mathbf{B}$, os quais significam:

A) comportar-se com integridade, demonstrando forte compromisso com os valores éticos e respeitando o Estado de Direito;

B) garantir a abertura e envolvimento abrangente dos stakeholders.

Além das principais exigências para agir no interesse público conforme os princípios $\mathbf{A}$ e $\mathbf{B}$, para se alcançar a boa governança no setor público também se requer a implementação dos seguintes mecanismos (princípios $\mathbf{C}$ a $\mathbf{G}$ ):

C) definir impactos em termos de desenvolvimentos sustentáveis econômico, social e ambiental;

D) determinar as intervenções necessárias para otimizar o alcance dos resultados pretendidos;

E) desenvolver a capacidade da instituição, inclusive de sua liderança e de seus empregados;

F) gerenciar riscos e desempenho por meio de controle interno robusto e gestão financeira pública forte;

G) implementar boas práticas de transparência, relatórios e auditoria para cumprir eficaz accountability. 
Os princípios A e B permeiam a implementação dos mecanismos C a G. Portanto, a boa governança é entendida como um processo dinâmico, e a entidade, como um todo, deve estar comprometida com a melhoria da governança de forma contínua, por meio de um processo de avaliação e revisão de seus procedimentos (IFAC, 2014).

\subsection{Consolidação dos instrumentos de governança do setor público}

A análise dos diversos instrumentos de governança indicou que se poderia consolidá-los e vislumbrar a convergência dos princípios de governança no setor público. Para visualizar esta questão, construiu-se o Quadro 1 com base nos princípios dos instrumentos de cada uma das seguintes instituições e/ou órgãos: CIPFA (2004), CLAD (2006), IMF (2007), Netherlands (2009), Unidet States (2011), IIA (2012), ANAO (2014), IFAC (2014) e TCU (BRASIL, 2014), cujas orientações estão direcionadas para o setor público. 
Luzia Zorzal; Georgete Medleg Rodrigues

Disclosure e transparência no setor público: uma análise da convergência dos princípios de governança

Quadro 1 - Consolidação dos instrumentos de governança do setor público

\begin{tabular}{|c|c|c|c|c|c|c|c|}
\hline \multirow{2}{*}{$\begin{array}{l}\text { Entidade } \\
\text { /Órgão }\end{array}$} & \multicolumn{7}{|c|}{ Dimensões } \\
\hline & A & B & C & D & E & $\mathbf{F}$ & G \\
\hline $\begin{array}{l}\text { CIPFA } \\
(2004)\end{array}$ & $\begin{array}{l}\text { Boa governança } \\
\text { por meio do } \\
\text { comportamento }\end{array}$ & $\begin{array}{l}\text { Envolvimento } \\
\text { com } \\
\text { stakeholders }\end{array}$ & $\begin{array}{l}\text { Foco na } \\
\text { organização e } \\
\text { resultados para } \\
\text { os cidadãos }\end{array}$ & Eficácia & Liderança & $\begin{array}{l}\text { Gerencia- } \\
\text { mento de } \\
\text { riscos }\end{array}$ & $\begin{array}{l}\text { Transparência, } \\
\text { accountability }\end{array}$ \\
\hline $\begin{array}{l}\text { CLAD } \\
(2006)\end{array}$ & $\begin{array}{c}\text { Integridade, } \\
\text { austeridade, } \\
\text { imparcialidade }\end{array}$ & $\begin{array}{l}\text { Igualdade, } \\
\text { respeito aos } \\
\text { direitos } \\
\text { humanos }\end{array}$ & $\begin{array}{c}\text { Responsa- } \\
\text { bilidade, } \\
\text { diversidade } \\
\text { étnica, cultural } \\
\text { e ambiental }\end{array}$ & Eficácia & $\begin{array}{c}\text { Dedicação ao } \\
\text { serviço }\end{array}$ & - & $\begin{array}{l}\text { Transparência, } \\
\text { acessibilidade }\end{array}$ \\
\hline $\begin{array}{l}\text { IMF } \\
(2007)\end{array}$ & $\begin{array}{l}\text { Garantias de } \\
\text { integridade }\end{array}$ & $\begin{array}{l}\text { Abertura, } \\
\text { processos } \\
\text { orçamentá- } \\
\text { rios }\end{array}$ & $\begin{array}{l}\text { Responsa- } \\
\text { bilidade }\end{array}$ & - & $\begin{array}{l}\text { Definição } \\
\text { clara de } \\
\text { funções }\end{array}$ & - & $\begin{array}{l}\text { Acesso à } \\
\text { informação } \\
\text { pública }\end{array}$ \\
\hline $\begin{array}{l}\text { Nether- } \\
\text { lands } \\
(2009)\end{array}$ & $\begin{array}{l}\text { Integridade e } \\
\text { legitimidade }\end{array}$ & $\begin{array}{c}\text { Abertura, } \\
\text { participação, } \\
\text { contato com o } \\
\text { público }\end{array}$ & - & $\begin{array}{l}\text { Eficácia e } \\
\text { eficiência }\end{array}$ & $\begin{array}{c}\text { Aprendi- } \\
\text { zagem, } \\
\text { Autoaperfei- } \\
\text { çoamento }\end{array}$ & - & Accountability \\
\hline $\begin{array}{l}\text { UNIDET } \\
\text { STATES } \\
(2011) \\
\end{array}$ & - & - & $\begin{array}{l}\text { Sustenta- } \\
\text { bilidade }\end{array}$ & Eficácia & Liderança & - & Accountability \\
\hline $\begin{array}{c}\text { IIA } \\
(2012) \\
\end{array}$ & Integridade & Equidade & - & - & - & - & $\begin{array}{l}\text { Transparência, } \\
\text { accountability }\end{array}$ \\
\hline $\begin{array}{c}\text { TCU } \\
\text { (BRASIL, } \\
\text { 2014) }\end{array}$ & $\begin{array}{l}\text { Legitimidade e } \\
\text { probidade }\end{array}$ & Equidade & $\begin{array}{l}\text { Responsa- } \\
\text { bilidade }\end{array}$ & Eficiência & - & - & $\begin{array}{l}\text { Transparência, } \\
\text { accountability }\end{array}$ \\
\hline $\begin{array}{l}\text { ANAO } \\
(2014)\end{array}$ & Integridade & Abertura & - & $\begin{array}{l}\text { Desem- } \\
\text { penho }\end{array}$ & - & $\begin{array}{l}\text { Reconheci- } \\
\text { mento de } \\
\text { riscos }\end{array}$ & $\begin{array}{l}\text { Transparência, } \\
\text { accountability }\end{array}$ \\
\hline $\begin{array}{l}\text { IFAC } \\
(2014)\end{array}$ & $\begin{array}{l}\text { Integridade, ética } \\
\text { e respeito às leis }\end{array}$ & $\begin{array}{c}\text { Abertura, } \\
\text { envolvimento } \\
\text { com } \\
\text { stakeholders }\end{array}$ & $\begin{array}{l}\text { Desenvol- } \\
\text { vimento } \\
\text { sustentável }\end{array}$ & $\begin{array}{l}\text { Otimizaçã } \\
\text { o de } \\
\text { resultado }\end{array}$ & Liderança & $\begin{array}{c}\text { Gerencia- } \\
\text { mento de } \\
\text { riscos e } \\
\text { desempenho }\end{array}$ & $\begin{array}{l}\text { Transparência, } \\
\text { accountability }\end{array}$ \\
\hline
\end{tabular}

Fonte: Elaboração própria com base nos instrumentos de governança.

Legenda: CIPFA - Chartered Institute of Public Finance and Accountancy; CLAD - Centro Latinoamericano de Administración para el Desarrollo; IMF - International Monetary Fund; IIA - Institute of Internal Auditors; TCU - Tribunal de Contas; ANAO - Australian National Audit Office; IFAC - International Federation of Accountants.

\section{Para a elaboração do Quadro 1, tomou-se por base a IFAC} (2014) que, pela pesquisa, nos respectivos sítios eletrônicos, apresentava a publicação mais recente (2-7-2014), por ser uma federação internacional e também por emitir Normas Internacionais de Contabilidade aplicadas ao setor público (International Public Sector Accounting Standards-IPSAS), dentre outros estudos que realiza para o cumprimento de sua missão. 
Outro fator para a escolha dos princípios da IFAC, como categoria de análise, é a publicação em 2014 de um estudo dessa federação em conjunto com a CIPFA. Esta última já havia divulgado, em 2004, o documento The good governance standard for public services (CIPFA, 2004), identificado, na literatura, como um dos primeiros instrumentos divulgados acerca do setor público, superado apenas pelo da ANAO, publicado em 2003, e que apresentou nova versão em 2014.

A partir dos sete princípios da IFAC (2014), ordenados de A a G, elaborou-se as colunas também com as denominações de $\mathbf{A}$ a $\mathbf{G}$. As instituições e/ou órgãos aparecem em ordem cronológica de divulgação dos seus respectivos instrumentos. A inserção dos significados, no Quadro 1, de cada um dos princípios e/ou dimensão dos respectivos órgãos, com exceção para os da IFAC, foi feita com base na análise de conteúdo (BARDIN, 2004) por similaridades dos termos e/ou significado, adequação e pertinência de cada um dos princípios e/ou dimensão do próprio instrumento, tentando-se buscar o mais próximo possível aos da IFAC, pois esses princípios foram tomados como categoria de análise. Quanto aos princípios da IFAC (2014), eles aparecem na ordem da própria instituição (A a $\mathbf{G})$.

Uma das análises do quadro mostra que, dos nove instrumentos analisados, cinco se referem à década atual, ou seja, 55,5\% deles são de 2010 para cá e, desses cinco, três (60\%) foram publicados em 2014. Isso demonstra que a discussão sobre o tema governança no setor público é recente. Quando se trata de Brasil, isso é mais evidente, pois o primeiro RBG (BRASIL, 2014), aplicável a órgãos e entidades da administração pública somente foi divulgado no ano de 2014.

O quadro permite evidenciar que há uma convergência dos princípios dentro das dimensões para os nove instrumentos analisados. A única dimensão que converge totalmente é a $\mathbf{G}$, na qual estão os princípios de transparência e accountability. Nessa dimensão também foram inseridos, quando constavam dos princípios, o acesso à informação pública e/ou a acessibilidade. O princípio da transparência 
está explícito em seis $(66,7)$ dos instrumentos verificados e a accountability em sete $(77,7 \%)$, o que equivale a dizer que $66,7 \%$ dos instrumentos estabelecem a transparência e 77,7\%, a accountability como princípios de boa governança.

Entretanto, em uma análise mais detida, pode-se considerar que $100 \%$ dos instrumentos estabelecem a transparência como um dos princípios, isso porque aqueles que não usaram o termo transparente, ou transparência, atingem a transparência, ou pelo termo abertura (situação dos instrumentos do IMF e Netherlands, na dimensão B) ou pelo termo accountability (caso da HM, na dimensão G). O termo abertura (openness) é definindo pela IFAC (2001) como estar aberto por meio de consulta significativa aos stakeholders e a comunicação de informações completas, precisas e claras. Ressalta, ainda, que abertura é mais do que as estruturas e processos. É também uma atitude e crença entre os principais gestores, políticos, funcionários públicos e outros stakeholders por quem a informação deve ser compartilhada e não é propriedade de qualquer entidade particular; é um recurso público.

A dimensão G tem como princípio "[...] implementar boas práticas de transparência, relatórios e auditoria, para cumprir eficaz accountability [...]" (IFAC, 2014, p. 10, tradução nossa). A accountability assegura que os tomadores de decisão são responsáveis pelas suas ações e devem prestar contas por elas. Segundo a IFAC (2014), a accountability eficaz está preocupada não só com o relato sobre as ações concluídas, mas também em responder como se desenvolvem os planos e atividades da instituição de uma forma transparente e garantir que os stakeholders sejam capazes de compreender essas ações (IFAC, 2014).

Dessa perspectiva, infere-se que, em todos os instrumentos de governança analisados, entre outros requisitos, exige-se que as organizações do setor público sejam transparentes, responsáveis por suas ações e que prestem contas (accountability) de suas atividades. Ao implementarem as práticas de boa governança, poderão mitigar a 
assimetria de informação, e assim os stakeholders poderão exercer melhor a cidadania e a democracia.

Os principais interessados em conhecer se os recursos públicos estão sendo aplicados adequadamente e o que está sendo gerado com eles são os cidadãos (stakeholders). Na condição de pagadores de tributos, eles devem exercer o seu direito de controle sobre os recursos que pagam aos cofres públicos.

Segundo constatação do Instituto Brasileiro de Planejamento e Tributação (IBPT), o Brasil está entre os 30 países de maior carga tributária do mundo, mas continua oferecendo os piores serviços à população em termos de saúde, educação, transporte, segurança, saneamento, pavimentação das estradas e outros (AMARAL; OLENIKE; AMARAL, 2014).

A transparência na gestão pública deve ser vista como uma condição essencial para que os países possam progredir no processo de desenvolvimento socioeconômico e na consolidação da democracia. Nesse contexto, a transparência do Estado se efetiva por meio do acesso do cidadão à informação governamental, o que torna mais democráticas as relações entre o Estado e a sociedade civil (MATIASPEREIRA, 2010a). Esse acesso deve se efetivar por meio da transparência ativa.

Como salientado por Matias-Pereira (2010b), os princípios de governança no setor público não são diferentes dos aplicados no setor privado. A diferença básica é que, nas instituições públicas, os gestores têm sob sua responsabilidade bens que pertencem à sociedade e cuja gestão deve ser feita com elevado nível de compromisso, responsabilidade, transparência, ética e senso de justiça.

As afirmações de Haswani (2013) complementam o argumento do parágrafo anterior apresentando uma diferença essencial que estabelece limites inquestionáveis entre o setor público e o privado: empresas privadas pertencem a alguns proprietários que as sustentam e delas retiram suas vantagens quando lucrativas ou suportam prejuízos 
quando não apresentam resultados favoráveis; já as instituições públicas pertencem a todos que a sustentam e, tendo sucesso ou fracasso, eles serão compartilhados com toda a sociedade.

\section{CONCLUSÕES}

Neste artigo, buscou-se aprofundar a reflexão sobre os instrumentos de governança, tendo como eixo a relação entre os princípios do disclosure e da transparência no âmbito da gestão pública. Como conclusão da análise comparativa dos conceitos analisados, ressalta-se que a boa governança não decorre apenas da efetivação de um princípio ou outro, mas requer a sinergia simultânea do conjunto em ação. Isso significa que envolve todas as dimensões institucionais e organizacionais, portanto será alcançada plenamente quando todos os seus princípios forem implementados. Como toda sistematização, esta também possui limitações, mas supõe-se que a consolidação apresentada seja útil para alargar o conhecimento comparativo sobre as diferentes ênfases dadas pelas instituições que têm teorizado sobre 0 assunto.

Ademais, não se esgota o tema, mas os resultados parciais indicam que as instituições públicas devem se preocupar em implantar boas práticas de governança, principalmente com relação ao princípio da transparência, por ser uma forma de suavizar a assimetria informacional e por ser, no Brasil, uma exigência da Lei, além de democratizar as relações entre Estado e cidadãos.

Para uma verdadeira democracia, torna-se imprescindível que as entidades públicas disponibilizem, proativamente, informações que sejam de interesse coletivo, mas, para tanto, é necessário que haja transparência. Em outras palavras, é fundamental que as informações sejam "publicizadas", compreensíveis, precisas, tempestivas, confiáveis, para entregar eficaz accountability, além de poder contribuir para reduzir a corrupção. Outro benefício é que, ao se ampliar a transparência ativa, 
há a possibilidade de se evitar custos, pois poderá haver redução de demandas de informações (transparência passiva).

\section{REFERÊNCIAS}

ALCHIAN, Armen A.; DEMSETZ, Harold. Production, information costs and economic organization. The American Economic Review, v. 62, n. 5, p. 777-795, 1972.

AMARAL, G. L.; OLENIKE, J. E.; AMARAL, L. F. (Coord.). Carga tributária x PIB x IDH. Curitiba: IBPT, 2014.

ANAO - AUSTRALIAN NATIONAL AUDIT OFFICE. Public sector governance: strengthening performance through good governance. 2014. Disponível em: <http://www.anao.gov.au/Publications/BetterPractice-Guides/2013-2014/Public-Sector-Governance>. Acesso em: 22 jul. 2014.

BARDIN, Laurence. Análise de conteúdo. 3. ed. Lisboa: Edições 70, 2004.

BENNIS, Warren et al. Transparência: como criar uma cultura de valores essenciais nas organizações. Rio de Janeiro: Elsevier, 2008.

BRASIL. Constituição (1988). Constituição [da] República Federativa do Brasil.1988. Disponível em:

<http://www.planalto.gov.br/ccivil_03/Constituicao/Constituicao.htm>. Acesso em: 30 set. 2013.

BRASIL. Decreto no 7.724, de 16 de maio de 2012. Regulamenta a Lei ํo 12.527, de 18 de novembro de 2011, que dispõe sobre o acesso a informações previsto no inciso XXXIII do caput do art. 5o, no inciso II do $\S$ 3o do art. 37 e no $\S 2$ o do art. 216 da Constituição. Disponível em:

<http://www.planalto.gov.br/CCIVIL_03/_Ato20112014/

2012/Decreto/D7724.htm>. Acesso em: 30 set. 2013.

BRASIL. Lei Complementar no 101, de 4 de maio de 2000. Estabelece normas de finanças públicas voltadas para a responsabilidade na gestão fiscal e dá outras providências. Disponível em:

<http://www.planalto.gov.br/ccivil_03/Leis/LCP/Lcp101.htm>. Acesso em: 23 maio 2013. 
BRASIL. Lei Complementar no 131, de 27 de maio de 2009.

Acrescenta dispositivos à Lei Complementar n.101, de 4 de maio de 2000, que estabelece normas de finanças públicas voltadas para a responsabilidade na gestão fiscal e dá outras providências, a fim de determinar a disponibilização, em tempo real, de informações pormenorizadas sobre a execução orçamentária e financeira da União, dos Estados, do Distrito Federal e dos Municípios. Disponível em: <http://www.planalto.gov.br/ ccivil_03/Leis/LCP/Lcp131.htm>. Acesso em: 1 out. 2013.

BRASIL. Lei no 12.527, de 18 de novembro de 2011. Regula o acesso a informações previsto no inciso XXXIII do art. 50, no inciso II do $\S 3$ o do art. 37 e no $\S 20$ do art. 216 da Constituição Federal; altera a Lei no 8.112, de 11 de dezembro de 1990; revoga a Lei no 11.111, de 5 de maio de 2005, e dispositivos da Lei no 8.159, de 8 de janeiro de 1991 e dá outras providências. Disponível em: <http://www.planalto.gov.br/ccivil_ 03/_Ato2011-2014/2011/Lei/L12527.htm>. Acesso em: 30 set. 2013.

BRASIL. Tribunal de Contas da União (TCU). Governança pública: referencial básico de governança aplicável a órgãos e entidades da administração pública e ações indutoras de melhoria. Brasília: TCU, Secretaria de Planejamento, Governança e Gestão, 2014. Disponível em: <http://portal2.tcu.gov.br/portal/pls/portal/docs/ 2642557.PDF>. Acesso em: 21 jul. 2014.

CENTRO LATINOAMERICANO DE ADMINISTRACIÓN PARA EL DESARROLLO - CLAD. Código iberoamericano de buen gobierno. Jun. 2006. Disponível em: <http:// old.clad.org/ documentos/declaraciones/codigoiber.pdf/view>. Acesso em: 13 out. 2013.

CHEVALIER, Jacques. Le mythe de la transparence administrative. In: C.U.R.A.P.P. Information et transparence administrative. Paris: PUF, 1988. p. 239-275. Disponível em: <http://www.upicardie.fr/labo/curapp/revues/root/21/chevallier.pdf>. Acesso em: 2 abr. 2014.

CIPFA - CHARTERED INSTITUTE OF PUBLIC FINANCE AND ACCOUNTANCY. Good governance standard for public services. 2004. Disponível em: <http://www.jrf.org.uk/system/files/ 1898531862.pdf>. Acesso em: 17 maio 2014.

COASE, Ronald. $\mathrm{H}$. The nature of the firm. Economica, London, v. 4, n. 16, p. 386-405, 1937.

ECGI - EUROPEAN CORPORATE GOVERNANCE INSTITUTE. Index of code. Disponível em: <http://www.ecgi.org/codes/all_codes.php>. Acesso em: 18 maio 2014. 
EDWARDS, Meredith et al. Public sector governance in Australia. Canberra, Austrália: ANU E Press, 2012.

FOX, Jonathan $A$. The uncertain relationship between transparency and accountability. Development in Practice, Oxford, v. 17, n. 4-5, p. 662671, Aug. 2007. Disponível em: <http://escholarship.org/uc/item/8c25c3z4>. Acesso em: 14 out 2013.

GIBBINS, Michael; RICHARDSON, Alan; WATERHOUSE, John. The management of corporate financial disclosure: opportunism, ritualism, policies and processes. Journal of Accounting Research, Chicago, v. 28, n. 1, p. 121-143, 1990.

HASWANI, Mariângela Furlan. Comunicação pública: bases e abrangências. São Paulo: Saraiva, 2013.

IBGC - INSTITUTO BRASILEIRO DE GOVERNANÇA CORPORATIVA. Código das melhores práticas de governança corporativa. 4. ed. São Paulo: IBGC, 2009.

IFAC - INTERNATIONAL FEDERATION OF ACCOUNTANTS. Public Sector Committtee. Governance in the public sector: a governing body perspective. 2001. Disponível em:

<http://www.ifac.org/sites/default/files/publications/files/study-13governance-in-th. pdf $>$. Acesso em: 7 out. 2013.

IFAC - INTERNATIONAL FEDERATION OF ACCOUNTANTS. Public Sector Committtee. International framework: good governance in the public sector. 2014. Disponível em: <https://www.ifac.org/publicationsresources/international-framework-good-governance-public-sector>. Acesso em: 18 jul. 2014.

IIA - INSTITUTE OF INTERNAL AUDITORS. Leading practice: transparency of the internal audit report in the public sector. Dec. 2012. Disponível em: <https://na.theiia.org/standardsguidance/Public\%20Documents/ Transparency\%20of\%20the\%20Internal\%20Audit\%20Report\%20in\%20t he\%20Public\%20Sector.pdf >. Acesso em: 17 maio 2014.

IMF - INTERNATIONAL MONETARY FUND. Code of good practices on fiscal transparency. 2007. Disponível em: <http://www.imf.org/external/np/pp/2007/eng/ 051507c.pdf>. Acesso em: 17 maio 2014.

JARDIM, Jose Maria. Transparência e opacidade do Estado no Brasil: usos e desusos da informação governamental. Niterói: EdUFF, 1999. 
JENSEN, Michael C.; MECKLING, William H. Theory of the firm: managerial behavior, agency costs and ownership structure. Journal of Financial Economics, Lausanne, v. 3, n. 4, p. 305-360, 1976.

KAPLAN, Robert S.; NORTON, David P. A estratégia em ação: balanced scorecard. 5. ed. Rio de Janeiro: Campus, 1997.

KLEIN, Benjamim. Contracting costs and residual claims: the separation of ownership and control. Journal of Law and Economics, Chicago, v. 26, n. 2, p. 367-374, 1983.

MALLIN, Christine. A. Corporate governance. $4^{\text {th }}$ ed. Oxford-UK: Oxford University Press, 2013.

MARQUES, Maria da Conceição da Costa. Aplicação dos princípios da governança corporativa ao setor público. Revista de Administração Contemporânea, Curitiba, v. 11, n. 2, p. 11-26, abr./jun. 2007.

MATIAS-PEREIRA, Jose. Curso de administração pública: foco nas instituições e ações governamentais. 3. ed. São Paulo: Atlas, 2010a.

MATIAS-PEREIRA, Jose. Governança no setor público. São Paulo: Atlas, 2010b.

MATTELART, Armand. História da sociedade da informação.

Tradução de Nicolás Nyimi Campanário. São Paulo: Edições Loyola, 2002.

MICHENER, Greg. Liberdade de Informação: uma síntese dos dilemas de conformidade suas possíveis soluções. In: ARTIGO 19. Leis de acesso à informação: dilemas da implementação. 2011. Disponível em:

MIGUEL, Luis Felipe. Democracia e representação: territórios em disputa. São Paulo: Ed. Unesp, 2014.

MURCIA, Fernando Dal-Ri. Fatores determinantes do nível de disclosure voluntário de companhias abertas no Brasil. 2009, $181 \mathrm{f}$. Tese (Doutorado em Controladoria e Contabilidade) - Universidade de São Paulo, São Paulo, 2009.

NETHERLANDS. Ministry of Finance. Government governance: corporate governance in the public sector, why and how? 2000. Disponível em:

<http://www.ecgi.org/codes/documents/public_sector.pdf>. Acesso em: 20 jul. 2014.

NOGUEIRA, Marco Aurelio. As possibilidades da política: ideias para a reforma democrática do Estado. São Paulo: Paz e Terra, 1998. 
OECD - ORGANISATION FOR ECONOMIC CO-OPERATION AND DEVELOPMENT. OECD principles of corporate governance. França, 2004. Disponível em:

<http://www.oecd.org/daf/ca/corporategovernanceprinciples/ 31557724. pdf>. Acesso em: 4 out. 2013.

RODRIGUES, Georgete Medleg. Indicadores de "transparência ativa" em instituições públicas: análise dos portais de universidades públicas federais. Liinc em Revista, Rio de Janeiro, v. 9, n. 2, p. 423-438, nov. 2013.

ROSS, Stephen A. The economic theory of agency: the principal's problem. The American Economic Review, Nashville, v. 63, n. 2, p. 134-139, May 1973.

ROSSETTI, Jose Paschoal; ANDRADE, Adriana. Governança corporativa: fundamentos, desenvolvimentos e tendências. 6. ed. São Paulo: Atlas, 2012.

SCHNACKENBERG, Andrew K.; TOMLINSON, Edward C.

Organizational transparency: a new perspective on managing trust in organization-stakeholder relationships. Journal of Management, Okla, v. XX, n. X, p. 1-27, 2014.

SILVEIRA, Antônio Maria. Governança corporativa no Brasil e no mundo: teoria e prática. Rio de Janeiro: Elsevier, 2010.

SLOMSKI, Valmor et al. Governança corporativa e governança na gestão pública. São Paulo: Atlas, 2008.

SLOMSKI, Valmor. Controladoria e governança na gestão pública. São Paulo: Atlas, 2005.

STIGLITZ, Joseph. Transparency in government. In: WORLD BANK INSTITUTE. The right to tell: the role of mass media in economic development. Washington, D.C: The World Bank, 2002. p. 27-44

TAPSCOTT, Don; TICOLL, David. A empresa transparente. São Paulo: M. Books, 2005.

UNIDET STATES. HM Treasury. Corporate governance in central government departaments: code of good practice. 2011. Disponível em: <https://www.gov.uk/government/publications/corporategovernance-code-for-central-government-departments>. Acesso em: 17 maio 2014. 
Luzia Zorzal; Georgete Medleg Rodrigues

Disclosure e transparência no setor público: uma análise da convergência dos princípios de governança

WILLIAMS, Cynthia Clark. Toward a taxonomy of corporate reporting strategies. Journal of Business Communication, v. 45, n. 3, p. 232264, July 2008.

WORLD BANK. Governance and development. Washington D.C., 1992.

\title{
Title
}

Diclosure and transparency in public sector: an analysis of convergence of the principles of governance

\begin{abstract}
Introduction: Studies on disclosure of private institutions are common, but do not occur when it comes to public institutions, where the disclosure of management is still very limited.

Purpose: The article is part of doctorate research in Information Science in progress and investigates the principles of disclosure and transparency in the light of good governance practices applied to the public sector, to reduce information asymmetry and presents part of this research.

Methodology: The methodological procedures were performed literature search and content analysis to identify the principles and standards of good governance practices recommended for public administration, aiming to systematize these recommendations as instruments of governance and verify the convergence of the principles of disclosure and transparency.

Results: Partial results show convergence of disclosure and transparency principles. Conclusions: Indicate that public institutions should worry about performing the practices of good governance as a way to mitigate the informational asymmetry.
\end{abstract}

Keywords: Transparency. Disclosure. Governance. Access to information. Information asymmetry. Public sector.

\section{Titulo}

Divulgación y transparencia en el sector público: un análisis de la convergencia de los principios de gobierno

\section{Resumen}

Introducción: Los estudios sobre la divulgación de las instituciones privadas son comunes, pero no se producen cuando se trata de las instituciones 
Luzia Zorzal; Georgete Medleg Rodrigues

Disclosure e transparência no setor público: uma análise da convergência dos princípios de governança

públicas, en que la divulgación de información de gestión es todavía muy limitada.

Propósito: El artículo es parte de una investigación de doctorado en Ciencias de la Información en curso y investiga los principios de publicidad y transparencia a la luz de las buenas prácticas de gobierno aplicadas al sector público para reducir la asimetría de información y presenta parte de esta investigación.

Metodología: Se realizaron los procedimientos metodológicos búsqueda bibliográfica y análisis de contenido para identificar los principios y normas de buenas prácticas de gobierno recomendadas para la administración pública, con el objetivo de sistematizar estas recomendaciones como instrumentos de gobierno y verificar la convergencia de los principios de publicidad y transparencia.

Resultados: Los resultados parciales muestran la convergencia de los principios de publicidad y transparencia.

Conclusiones: Indican que las instituciones públicas deben preocuparse acerca de la implementación de las prácticas de buen gobierno como una forma de mitigar la asimetría informativa.

Palabras clave: Transparencia. divulgación. Gobernabilidad. El acceso a la información. Asimetría de información. Sector público.

Recebido em: 14/08/2014

Aceito em: 28/03/2015 